\title{
Suturing the mucosal defect after ESD
}

\section{(ㄷ)(1) $(2)$}

\author{
Authors \\ Motohiko Kato, Naohisa Yahagi \\ Institution \\ Division of Research and Development for Minimally \\ Invasive Treatment, Cancer Center, Keio University School \\ of Medicine, Tokyo, Japan \\ Bibliography \\ DOI https://doi.org/10.1055/a-1216-1717 | \\ Endoscopy International Open 2020; 08: E1218-E1219 \\ (c) Georg Thieme Verlag KG Stuttgart · New York \\ elSSN 2196-9736
}

\author{
Corresponding author \\ Motohiko Kato, MD, PhD, Division of Research and \\ Development for Minimally Invasive Treatment, Cancer \\ Center, Keio University School of Medicine, 35 \\ Shinanomachi, Shinjuku-ku, Tokyo, Japan \\ Fax: +81-3-3353-6247 \\ moto28hiko@icloud.com
}

With recent progress in technology and improvement in medical devices, outcomes of endoscopic submucosal dissection (ESD) have improved, however, delayed adverse events (AEs) including bleeding and perforation have remained major concern [1]. In particular, the number of patients taking anticoagulants is increasing and risk of delayed bleeding reportedly is significantly higher in these patients, therefore, prevention of delayed AEs is a major concern to be solved.

In this issue of Endoscopy International Open, Han et al. tried to assess the feasibility of endoscopic suturing using overstitch to prevent AEs in patients undergoing gastric and rectal ESD. They prospectively collected a total of 31 cases (18 gastric, 13 rectal) and accomplished $100 \%$ technical success in closing the mucosal defect with mean size of $38 \mathrm{~mm}$ with median suturing time of 13.4 minutes. More than half the patients were treated as day surgery and there were no AEs [2].

Several techniques have been reported for complete closure of post-ESD large mucosal defects [3]. Overstitch was first reported by Kantsevoy et al in 2014 [3] as a new endoscopic suturing platform attaching to a double-channel therapeutic endoscope. It enables full-thickness suturing using a cinching device. We also reported endoscopic hand suturing (EHS) of gastric mucosal defects [4] and an endoscopic string clip suturing method for closing mucosal defects after duodenal ESD [5]. These techniques reportedly can be used to securely close even a large mucosal defect created by ESD.

The most important advantage of closing mucosal defects is reducing $A E s$ after endoscopic resection. Recently, a randomized controlled trial revealed that closing the mucosal defect significantly reduces delayed bleeding after colonic polypectomy, especially in lesions located in the right-sided colon [6]. Furthermore, we recently reported that approximately $95 \%$ of the risk of delayed AEs was eliminated by suturing the mucosal defect using the string clip suturing method [7]. On the other hand, suturing a large mucosal defect after ESD requires time and cost. Both overstitch and EHS require an additional dedicated device for suturing, and the string clip suturing method requires skill on the part of the endoscopist and a number of endoclips. Furthermore, because the resection margin is sometimes uncertain, there is a risk of embedding tumor component into the submucosal layer in some cases. Considering these issues with suturing mucosal defects, it is important to identify patients who can benefit most from this technique. Patients at high risk of AEs, including those taking anticoagulants or undergoing wide field resection in the right-sided colon or in the duodenum, are thought to be distinct candidates. Another group are those undergoing ESD as same-day surgery, particularly in countries in which hospitalization is expensive. Of course, the situation may change if the technology becomes easier to use and less expensive in the future.

In conclusion, suturing mucosal defect after ESD would reduce AEs and be beneficial, especially in high-risk patients, although further improvement is necessary in order for its use to become widespread.

\section{Competing interests}

The authors declare that they have no conflict of interest.

\section{References}

[1] Yahagi N, Kato M, Ocihai Y et al. Outcomes of endoscopic resection for superficial duodenal epithelial neoplasia. Gastrointest Endosc 2018: doi:10.1016/j.gie.2018.05.002 
[2] Han S, Wanin S, Soetikno R. Feasibility of Endoscopic suturing to prevent adverse events and hospitalization after endoscopic submucosal dissection. Endosc Int Open 2020; 08: E1212-E1217

[3] Kantsevoy SV, Bitner M, Mitrakov AA et al. Endoscopic suturing closure of large mucosal defects after endoscopic submucosal dissection is technically feasible, fast, and eliminates the need for hospitalization (with videos). Gastrointest Endosc 2014; 79: 503-507

[4] Goto O, Oyama T, Ono H et al. Endoscopic hand-suturing is feasible, safe, and may reduce bleeding risk after gastric endoscopic submucosal dissection: a multicenter pilot study (with video). Gastrointest Endosc 2020; 91: 1195-1202
[5] Yahagi N, Nishizawa T, Akimoto T et al. New endoscopic suturing method: string clip suturing method. Gastrointest Endosc 2016; 84: 1064-1065

[6] Pohl H, Grimm IS, Moyer MT et al. Clip closure prevents bleeding after endoscopic resection of large colon polyps in a randomized trial. Gastroenterology 2019; 157: 977-984.e973

[7] Kato M, Ochiai Y, Fukuhara S et al. Clinical impact of closure of the mucosal defect after duodenal endoscopic submucosal dissection. Gastrointest Endosc 2019; 89: 87-93 